\title{
Clinical Outcomes of Minimally Invasive Posterior Cervical Decompression Using a Tubular Retractor for the Treatment of Cervical Spondylotic Myelopathy: Single-center Experience with a Minimum 12-month Follow-up
}

\author{
Ho-Jung Chung, Jung-Woo Hur, Kyeong-Sik Ryu, Jin-Sung Kim, Ji-Hoon Seong \\ Department of Neurosurgery, Seoul St. Mary's Hospital, The Catholic University of Korea, Seoul, Korea
}

\begin{abstract}
Objective: Recently, with the use of the tubular retractor system, minimally invasive posterior cervical decompression has become possible. Improvement of surgical technique has made reduction in tissue damage during operation possible, which allows less postoperative pain, and shorter hospital stays. The objective of this study is to evaluate the safety and efficacy of a minimally invasive surgical technique using a tubular retractor system. This study is a series of consecutive mid-term follow-up reports in controlled clinical trials held at the institute of the authors using a minimally invasive surgical technique. Methods: Twenty-one patients underwent minimally invasive posterior cervical decompression. Medical records including demographic data, diagnoses, complications, and degrees of symptom relief, were recorded and evaluated. Clinical outcomes were assessed by the neurological status and visual analog scale (VAS) score for neck and arm pain.

Results: Muscle weakness improved in all patients, of whom $80.9 \%$ (17/21) showed a complete resolution of sensory deficits and $19.1 \%(4 / 21)$ showed partial improvement. An analysis of the mean VAS and Neck Disability Index scores revealed significant improvement at the final follow-up. The mean Japanese Orthopedic Association scoring system for cervical myelopathy (C-JOA score) scores also improved from a preoperative value of $11.2 \pm 2.6$ to $16.2 \pm 3.1$ for the last follow-up. The recovery rate calculated using the Hirabayashi method was shown to have an average of $53.2 \pm 22.0 \%$.

Conclusion: Our short-term experiences with relatively good clinical outcomes imply that this minimally invasive technique is a valid alternative option for the treatment of cervical spondylotic myelopathy.
\end{abstract}

Key Words: Spondylosis $\cdot$ Minimally invasive surgical procedures $\cdot$ Cervical vertebrae

\section{INTRODUCTION}

Cervical spondylotic myelopathy (CSM) is one of the most common disorders of the cervical spine requiring surgical treatment. It is characterized by development and progression of degenerative changes associated with normal aging process. Cervical spinal stenosis patients have a tendency to suffer chronic myelopathy and high risk of acute spinal cord injury after traumatic injury. Mostly, cervical canal compromise result from two types of spinal degenerative processes, (1) ventral cord compression from bulging discs and osteophytes and (2) posterior compression by facet hypertrophy and thickening of the ligamenta flavum. The average anteroposterior diameter of a normal cervical canal on plain radiograph is $17 \mathrm{~mm}$, whe-

Corresponding author: Jung-Woo Hur

Department of Neurosurgery, Seoul St. Mary's Hospital, The Catholic University of Korea, 222 Banpo-daero, Seocho-gu, Seoul 06591, Korea Tel: +82-2-2258-6265, Fax: +82-2-594-4248

E-mail: neurotique79@gmail.com reas symptomatic stenosis generally occurs when the diameter is less than $13 \mathrm{~mm}^{33}$.

Various anterior and posterior surgical approaches for the treatment of CSM have been introduced, and studies have shown differing results depending on approaches, ${ }^{8,16,20-22,24,25,28)}$. Concerning the disadvantages of detaching the cervical paraspinal muscles from the laminae and the spinous processes in conventional posterior approaches ${ }^{7,26}$, anterior approach has become dominant among spinal surgeons, worldwide. Surgical trauma to the extensor cervical muscles in conventional posterior cervical operation is a major cause of various postoperative complications ${ }^{2,14,18,36}$, such as persistent neck and shoulder pain, postoperative kyphosis, spinal instability, etc. The current trend of favoring anterior approach surgery, even in patients with normal sagittal balance and posterior compressive pathology, is of great concern with the possibility of complications such as adjacent level disease and recurrent laryngeal and esophageal injury ${ }^{1,5,9,17)}$.

Recently, with the increasing popularity of minimally invasive techniques, the possibility of posterior cervical approach 
is gaining renewed interest ${ }^{4,6,13)}$. With the aid of a tubular retractor system, minimally invasive posterior cervical decompression has become possible, even in the multi-level cervical diseases. These evolutions of surgical techniques have led to a greater reduction in tissue damage during operation, which reduces postoperative pain, shortens hospital stays, quicker return to daily living activities.

The objective of this study is to introduce a novel minimally invasive surgical technique for multi-level posterior cervical decompression using a tubular retractor system and to evaluate safety and efficacy of this technique in short-term follow-up. This study is a series of consecutive mid-term follow-up reports in controlled clinical trials held at the institute of the authors using a minimally invasive surgical technique ${ }^{15}$.

\section{MATERIALS AND METHODS}

\section{Materials and Methods}

Twenty-one patients suffering from CSM underwent minimally invasive posterior cervical decompression using a tubular retractor. The operations were performed between April 2012 and May 2014. The indications for surgery were (1) presence of CSM confirmed by radiologic imaging studies, (2) presence of symptomatic myelopathy for more than 6 months, (3) compression ratio less than 0.4 , indicating flattening of the

Table 1. Patient demographics and intraoperative data

\begin{tabular}{lc}
\hline \hline Characteristics & Mean (SD) [range] \\
\hline Gender ( $[\%])$ & $9(42.9 \%)$ \\
Male & $12(57.1 \%)$ \\
Female & $56.7( \pm 14.1)$ \\
Age (years) & $26.3( \pm 3.4)$ \\
Body mass index & \\
Preoperative symptoms & $6.4( \pm 2.7)$ \\
VAS Neck Pain & $8.9( \pm 2.1)$ \\
VAS Radicular Pain & $17.4( \pm 8.7)$ \\
Duration of pain (months) & $1(4.8 \%)$ \\
Previous spinal surgeries (n [\%]) & $61( \pm 33)$ \\
Intraoperative blood loss (mL) & $73.3( \pm 21.4)$ \\
Operating time (min) & $1.4( \pm 1.5)$ \\
Length of hospital stay (days) & \\
Segments operated on & $8(38.1 \%)$ \\
1 segment & $4(19.0 \%)$ \\
2 segment & $9(42.9 \%)$ \\
3 segment &
\end{tabular}

spinal cord, (4) transverse area of the cord less than $40 \mathrm{~mm}^{2}$, (5) predominant dorsal cord compressing pathology such as ossification of the ligamenta flava (OLF), and (6) failure of conservative treatment over a period of 6 weeks. The exclusion criteria were cervical myelopathy with tumor, trauma, severe ossification of the posterior longitudinal ligament (OPLL), herniated disc, rheumatoid arthritis, pyogenic spondylitis, and the presence of other combined spinal lesions. The pathologic level and extent of spinal cord compression were confirmed by magnetic resonance imaging (MRI) and post-myelography computed tomography (CT). In addition, cervical MRI was performed in three different neck positions (neutral, flexion, and extension) in all patients to determine whether the spinal canal was dominantly compressed by posterior or anterior pathology. Patients with dominant anterior compression (such as multi-level intervertebral disc bulging) were excluded from the study and underwent surgery using an alternative anterior approach. The demographic and intraoperative data of the patients are listed in Table 1 . The study included 9 men and 12 women. All patients presented with symptoms of cervical myelopathy: clumsiness, numbness of the upper and lower extremities, gait disturbances, urinary disturbances, etc. The average age of the study subjects at the time of operation was $56.7 \pm 14.1$ years and the average body mass index was $26.3 \pm 3.4 \mathrm{~kg} / \mathrm{m}^{2}$. The mean visual analogue scale (VAS) scores of preoperative neck pain and radi- cular arm pain were 6.4 \pm 2.7 and 8.9 \pm 2.1 , respectively, and the average duration of pain was $17.4 \pm 8.7$ months. One of the patients had undergone previous anterior cervical fusion at a local clinic for a herniated disc. Eight patients were operated on at one segment, four patients at two segments, and nine patients at three segments.

The hospital charts and follow-up medical records of all patients were carefully reviewed. Outcomes were assessed preoperatively and postoperatively using the Japanese Orthopedic Association scoring system for cervical myelopathy (C-JOA score $)^{34)}$, recovery rate as calculated by Hirabayashi's method $^{12,34)}$, a modified version of the Oswestry Disability Index called the neck disability index $(\mathrm{NDI})^{30,38)}$, and VAS score for neck and radicular arm pain ${ }^{38)}$.

All parameters were statistically analyzed. The data are expressed as mean \pm standard deviation (SD). A result was considered statistically significant if the p-value was less than 0.05 .

\section{Surgical Technique}

Detailed surgical technique is introduced in our previous reports ${ }^{15)}$.

Before surgery, each patient underwent evaluation by dynamic radiographs to rule out obvious instability, and MRI 
or post-myelography CT to define the necessary extent of the surgery. The results of routine medical and laboratory evaluations were obtained. The anesthesia team was informed prior to the surgery of the possible need for fiberoptic intubation. The operation was done under general anesthesia and monitoring of interoperative somatosensory evoked potentials (SEP) was done in all patients.

\section{RESULTS}

Twenty-one patients underwent minimally invasive posterior cervical decompression using a tubular retractor system and a surgical microscope. The mean follow-up duration was $13 \pm$ 5.3 months. Average intraoperative blood loss was $61 \pm 33 \mathrm{~mL}$, average operating time was $73.3 \pm 21.4 \mathrm{~min}$, and average length of hospital stay was $1.4 \pm 1.5$ days (Table 1). Patients with sedentary jobs usually returned to work within a week after discharge. Muscle weakness improved in all patients. Sensory deficits resolved in 17 patients and improved in 4 patients. Analysis of the mean VAS scores for radicular pain and neck pain showed significant improvement compared to preoperative values at final follow-up (Fig. 1). The mean VAS score for neck pain decreased from $6.2 \pm 2.2$ to $5.8 \pm 2.0$ immediately post-operatively, reaching $2.1 \pm 1.3$ at 3 months and $1.8 \pm 0.9$ at the last follow-up visit. VAS scores for radicular
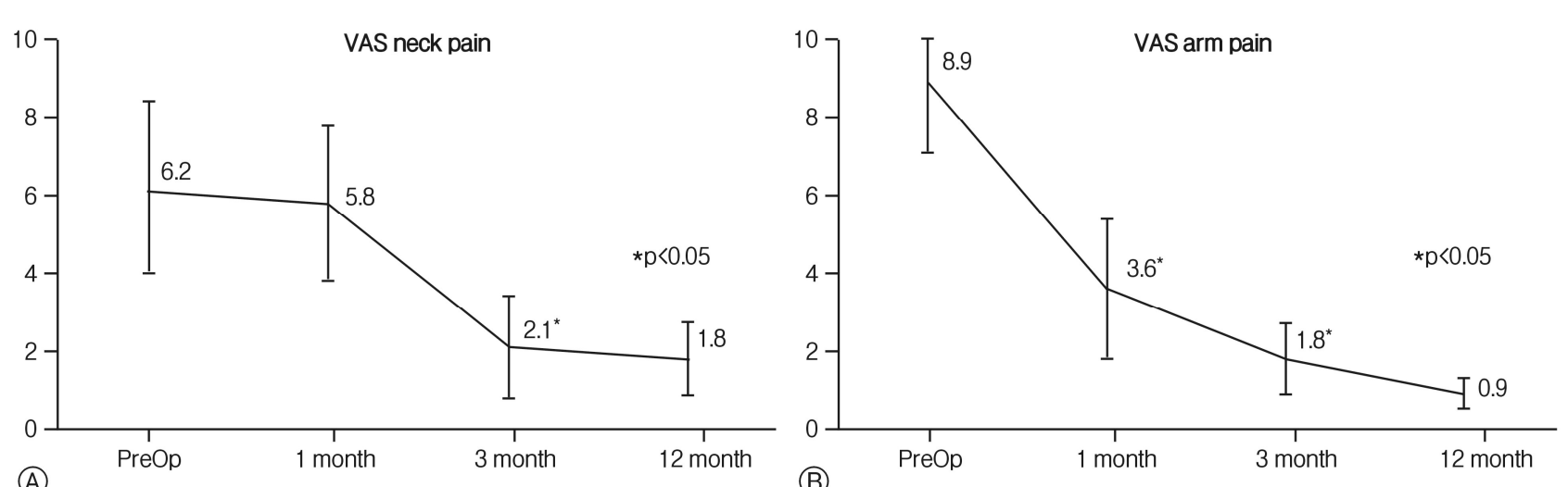

(B)

Selection of approach side for cervical spinal decompression usually depends on various factors, including extent of disease, sagittal curvature of the cervical spine, prior surgery, general condition of the patient, skill and familiarity of the surgeon, severity of canal compression, and intervertebral mobility at the level of maximum compression. The anterior approach offers a relatively simpler route to the spine and a means of decompressing the ventral spinal pathology than does the posterior approach. On the other hand, disadvantages of the anterior approach include potential complications involving anterior neck structures, dysphagia, recurrent laryngeal nerve

Fig. 1. Clinical results showing significant improvement after the surgery (A) Visual analog scale (VAS) scores for neck pain and (B) VAS scores for radicular arm pain. Op: operation.

Table 2. Japanese Orthopedic Association scoring system for cenvical myelopathy score and recovery rate calculated by Hirabayashi's method after surgery

\begin{tabular}{lccc}
\hline \hline & Preoperative & Final follow-up & $\mathrm{p}$-value \\
\hline C-JOA score (points) & $11.2 \pm 2.6$ & $16.2 \pm 3.1$ & $<0.05$ \\
Recovery rate* (\%) (JOA score) & - & $53.2 \pm 22.0$ & - \\
NDI (points) & $68.3 \pm 9.1$ & $13.3 \pm 10.4$ & $<0.05$ \\
\hline
\end{tabular}

"Recovery rate calculated by Hirabayashi's method. C-JOA: Japanese Orthopedic Association scoring system for cervical myelopathy; NDI: neck disability index. 
injury, and adjacent segment degeneration following loss of one or more motion segments.

Posterior decompression allows safer route for the thecal sac and avoids many of the risks of anterior exposure. However, ventral compressing pathologies such as disc herniation, osteophytes, or OPLL may be neglected when using a posterior approach. Although a simple multilevel laminectomy or laminoplasty is a relatively straightforward procedure, it often results in significant postoperative neck pain and longer hospitalization. In addition, CSF leakage, wound-related problems, postoperative kyphosis, and instability are not uncommon in conventional posterior operations.

With the recent advancement of specialized surgical instruments and access devices, minimally invasive spinal surgery has proven to be a useful tool for the treatment of various spinal diseases while minimizing soft tissue damage. Application of this technique to the cervical spine followed naturally, and posterior minimally invasive cervical surgery has been performed recently in many institutions to determine the feasibility and efficacy of such procedures. Recent studies using a trans-muscular working channel to perform minimally invasive decompression for radiculopathy and myelopathy concluded that the basic technique is safe and feasible ${ }^{4,32)}$.

There are a few reports of posterior cervical decompression using different minimally invasive techniques up to date. Routine three-position cervical MRI for cervical spondylotic myelopathic patients was performed in our series to evaluate the characteristics of canal compression and to aid in the surgeon's selection of an appropriate surgical technique. Cervical dynamic MRI is useful in accurately determining the number of levels in which the spinal cord is compromised, and evaluating the degree of narrowing of the spinal canal ${ }^{3,37}$. Using radio- logic information, we selected cases with more dorsal than ventral compression for this series. As mentioned above, individuals with more dominant anterior compression were excluded and underwent alternative anterior surgery. There are many important factors that influence the choice of approach and surgical technique in cervical spinal surgery, and dynamic MRI may provide crucial information.

A tubular retractor is able to provide a wide degree of visualization through a small skin incision and with the successive angulations of the working channel into a more medial position, the access to the contralateral dorsal spinal canal is allowed which make it superior to the unilateral open technique. Visualization of the spinal canal, ligamenta flavum, and existing nerve root interface is enhanced by an operating microscope, which provides a three-dimensional view; with the microscope-assisted procedure, we could accomplish bilateral decompression via a unilateral approach, so-called "unilateral approach for bilateral decompression (ULBD)" ${ }^{19,23,29)}$. During the procedure, repositioning the working channel more medially enabled us to drill the base of the spinous process and the ventral surface of the contralateral lamina. Exposure of the contralateral attachment of the ligamentum flavum is critical to ensuring adequate bilateral decompression, and it is important to keep the ligament intact in order to protect the spinal cord.

This minimally invasive posterior cervical decompression technique using the tubular retractor has many advantages, such as a small skin incision, gentle tissue dissection, excellent visualization, and the ability to achieve results equivalent to conventional open techniques. The open posterior cervical approach requires para-spinal muscle dissection and partial medial facetectomy. Stripping of the muscles may damage their innervation and blood supply, which may cause postoperative neck pain with temporary or persistent functional disturbances and possibly affect stability in multi-level procedures ${ }^{14,36}$. A minimal skin incision provides a better cosmetic effect and minimizes paraspinal muscle trauma, and contributes to a decrease in postoperative neck pain and dysfunction. Conventional laminoplasty causes cervical instability and kyphosis when more than $50 \%$ of a unilateral facet joint or $25 \%$ of bilateral facet joints are resected ${ }^{10)}$. Our minimally invasive technique can minimize facet joint resection using ULBD, which requires only partial hemilaminectomy to enlarge the size of the canal. Moreover, the operating time, estimated blood loss, and hospital stays were also smaller in our patients compared to published data on conventional open surgeries ${ }^{11,12,31,35)}$.

On the other hand, minimally invasive decompression carries a higher risk of dura and nerve injury, CSF leakage, and postoperative seroma formation compared to conventional laminectomy or laminoplasty ${ }^{4,27,32)}$. Because a high-speed drill is used to undercut spinous processes and contralateral lamina through a tubular retractor, the restricted operation field can lead to injury to the dura. Incidental durotomy can generally be managed by dural sealant materials, but persistent leakage may require direct repair followed by a lumbar drain. Careful use of bipolar cautery, both to minimize excessive bleeding from the venous plexus and to avoid neural injury, is an important consideration. The high-speed drill may cause local thermal injury, and careful irrigation must be ensured. Like any other minimally invasive technique, there is also a chance of postoperative seroma formation within 24 to $72 \mathrm{hr}$ after surgery. Owing to the smaller canal diameter in the cervical spine, a relatively small seroma can cause cord compression even though a postoperative drain is used. Moreover, as described in our case presentation, asymptomatic spinous process fracture is possible owing to lateral angulation of the tubular retractor in cases requiring additional foraminal decompression. We experienced two cases of single level spinous 
process fracture out of all study subjects, but neither had significant symptoms related to it.

Furthermore, spinal canal enlargement is somewhat limited compared to conventional posterior techniques in that one is not able to push down the dura to obtain a better view, as in lumbar surgeries. Decompression of canal stenosis which occurs due to posterior pathologic lesions such as OLF is very effective with this technique, but in the case of anterior cervical pathologic lesions or multi-level canal stenosis with more than three segments, and developmental canal stenosis, an anterior approach or conventional laminoplasty may be a better alternative option. Without the benefit of a wide viewing area, as is possible in conventional open surgery, the risk of incomplete decompression also exists, especially in inexperienced hands.

This study demonstrates the feasibility of decompressing the cervical spinal canal using a unilateral tubular technique. Minimally invasive surgical techniques involve a very steep learning curve and considerable experience is required to decompress the neural structures adequately. The operational field of a tubular retractor is limited, making it difficult to fully ascertain the amount of bony work that has been performed. Furthermore, working under a microscopic view can be disorienting. To ensure satisfactory canal decompression while maintaining the integrity of neural elements require relatively more training and experience. Long-term follow-up studies with larger sample sizes are required to determine the benefits of minimally invasive surgery compared with traditional open laminectomy.

\section{CONCLUSION}

In our clinical series of minimally invasive posterior cervical decompression using a tubular retractor system, we demonstrate the safety and relatively good clinical outcomes despite a limited number of patients and a short-term follow-up period. These techniques have the theoretical advantages of reducing morbidity, blood loss, perioperative pain, and length of hospital stay compared with conventional open posterior cervical approaches. This minimally invasive posterior technique could be a useful alternative when choosing a surgical method for cervical myelopathy. However, a steep learning curve is required for such a minimally invasive technique and a risk of possible complications, such as dura and nerve injury, CSF leakage, and postoperative seroma formation do exist. Further studies with more patients and longer follow-up are required to determine the exact benefits compared with conventional open surgery.

\section{REFERENCES}

1. Baba H, Furusawa N, Imura S, Kawahara N, Tsuchiya H, Tomita $\mathrm{K}$ : Late radiographic findings after anterior cervical fusion for spondylotic myeloradiculopathy. Spine (Phila Pa 1976) 18:21672173, 1993

2. Baba H, Maezawa Y, Furusawa N, Imura S, Tomita K: Flexibility and alignment of the cervical spine after laminoplasty for spondylotic myelopathy. A radiographic study. Int Orthop 19:116121, 1995

3. Bartlett RJ, Hill CA, Rigby AS, Chandrasekaran S, Narayanamurthy $\mathrm{H}$ : MRI of the cervical spine with neck extension: is it useful? Br J Radiol 85:1044-1051, 2012

4. Boehm H, Greiner-Perth R, El-Saghir H, Allam Y: A new minimally invasive posterior approach for the treatment of cervical radiculopathy and myelopathy: surgical technique and preliminary results. Eur Spine J 12:268-273, 2003

5. Bulger RF, Rejowski JE, Beatty RA: Vocal cord paralysis associated with anterior cervical fusion: considerations for prevention and treatment. J Neurosurg 62:657-661, 1985

6. Burke TG, Caputy A: Microendoscopic posterior cervical foraminotomy: a cadaveric model and clinical application for cervical radiculopathy. J Neurosurg 93:126-129, 2000

7. Epstein NE: Laminectomy for cervical myelopathy. Spinal Cord 41:317-327, 2003

8. George B, Gauthier N, Lot G: Multisegmental cervical spondylotic myelopathy and radiculopathy treated by multilevel oblique corpectomies without fusion. Neurosurgery 44:81-90, 1999

9. Gore DR, Sepic SB: Anterior cervical fusion for degenerated or protruded discs. A review of one hundred forty-six patients. Spine (Phila Pa 1976) 9:667-671, 1984

10. Henderson CM, Hennessy RG, Shuey HM, Jr., Shackelford EG: Posterior-lateral foraminotomy as an exclusive operative technique for cervical radiculopathy: a review of 846 consecutively operated cases. Neurosurgery 13:504-512, 1983

11. Herkowitz $\mathrm{HN}$ : A comparison of anterior cervical fusion, cervical laminectomy, and cervical laminoplasty for the surgical management of multiple level spondylotic radiculopathy. Spine (Phila Pa 1976) 13:774-780, 1988

12. Hirabayashi K, Watanabe K, Wakano K, Suzuki N, Satomi K, Ishii Y: Expansive open-door laminoplasty for cervical spinal stenotic myelopathy. Spine (Phila Pa 1976) 8:693-699, 1983

13. Holly LT, Moftakhar P, Khoo LT, Wang JC, Shamie N: Minimally invasive 2-level posterior cervical foraminotomy: preliminary clinical results. J Spinal Disord Tech 20:20-24, 2007

14. Hosono N, Yonenobu K, Ono K: Neck and shoulder pain after laminoplasty. A noticeable complication. Spine (Phila Pa 1976) 21:1969-1973, 1996

15. Hur JW, Kim JS, Shin MH, Ryu KS: Minimally invasive posterior cervical decompression using tubular retractor: The technical note and early clinical outcome. Surg Neurol Int 5:34, 2014

16. Jho HD: Decompression via microsurgical anterior foraminotomy for cervical spondylotic myelopathy. Technical note. J Neurosurg 86:297-302, 1997

17. Jung A, Schramm J, Lehnerdt K, Herberhold C: Recurrent laryn- 
geal nerve palsy during anterior cervical spine surgery: a prospective study. J Neurosurg Spine 2:123-127, 2005

18. Kawaguchi Y, Matsui H, Ishihara H, Gejo R, Yoshino O: Axial symptoms after en bloc cervical laminoplasty. J Spinal Disord 12:392-395, 1999

19. Kim JS, Jung B, Arbatti N, Lee SH: Surgical experience of unilateral laminectomy for bilateral decompression (ULBD) of ossified ligamentum flavum in the thoracic spine. Minim Invasive Neurosurg 52:74-78, 2009

20. Lee TT, Manzano GR, Green BA: Modified open-door cervical expansive laminoplasty for spondylotic myelopathy: operative technique, outcome, and predictors for gait improvement. J Neurosurg 86:64-68, 1997

21. Naderi S, Alberstone CD, Rupp FW, Benzel EC, Baldwin NG: Cervical spondylotic myelopathy treated with corpectomy: technique and results in 44 patients. Neurosurg Focus 1:e5, 1996

22. Onari K, Toguchi A, Kondo S, Mihara H, Hachiya M, Yamada $\mathrm{K}$ : Cervical posterior fusion with wave-shaped rod under local anesthesia for cervical spondylotic myelopathy: review of 12 patients. Spine (Phila Pa 1976) 26:2334-2339, 2001

23. Palmer S, Turner R, Palmer R: Bilateral decompression of lumbar spinal stenosis involving a unilateral approach with microscope and tubular retractor system. J Neurosurg 97:213-217, 2002

24. Sekhon LH: Cervical arthroplasty in the management of spondylotic myelopathy: 18-month results. Neurosurg Focus 17:E8, 2004

25. Shiraishi T: Skip laminectomy- -a new treatment for cervical spondylotic myelopathy, preserving bilateral muscular attachments to the spinous processes: a preliminary report. Spine J 2:108-115, 2002

26. Snow RB, Weiner H: Cervical laminectomy and foraminotomy as surgical treatment of cervical spondylosis: a follow-up study with analysis of failures. J Spinal Disord 6:245-250, 1993

27. Song JK, Christie SD: Minimally invasive cervical stenosis decompression. Neurosurg Clin N Am 17:423-428, 2006

28. Tani S, Isoshima A, Nagashima Y, Tomohiko Numoto R, Abe
T: Laminoplasty with preservation of posterior cervical elements: surgical technique. Neurosurgery 50:97-101, 2002

29. Tsai RY, Yang RS, Bray RS, Jr.: Microscopic laminotomies for degenerative lumbar spinal stenosis. J Spinal Disord 11:389-394, 1998

30. Vernon H, Mior S: The Neck Disability Index: a study of reliability and validity. J Manipulative Physiol Ther 14:409-415, 1991

31. Wada E, Suzuki S, Kanazawa A, Matsuoka T, Miyamoto S, Yonenobu K: Subtotal corpectomy versus laminoplasty for multilevel cervical spondylotic myelopathy: a long-term follow-up study over 10 years. Spine (Phila Pa 1976) 26:1443-1447, 2001

32. Wang MY, Green BA, Coscarella E, Baskaya MK, Levi AD, Guest JD: Minimally invasive cervical expansile laminoplasty: an initial cadaveric study. Neurosurgery 52:370-373, 2003

33. Wolf BS, Khilnani M, Malis L: The sagittal diameter of the bony cervical spinal canal and its significance in cervical spondylosis. J Mt Sinai Hosp N Y 23:283-292, 1956

34. Yonenobu K, Abumi K, Nagata K, Taketomi E, Ueyama K: Interobserver and intraobserver reliability of the japanese orthopaedic association scoring system for evaluation of cervical compression myelopathy. Spine (Phila Pa 1976) 26:1890-1894, 2001

35. Yonenobu K, Hosono N, Iwasaki M, Asano M, Ono K: Laminoplasty versus subtotal corpectomy. A comparative study of results in multisegmental cervical spondylotic myelopathy. Spine (Phila Pa 1976) 17:1281-1284, 1992

36. Zdeblick TA, Zou D, Warden KE, McCabe R, Kunz D, Vanderby R: Cervical stability after foraminotomy. A biomechanical in vitro analysis. J Bone Joint Surg Am 74:22-27, 1992

37. Zhang L, Zeitoun D, Rangel A, Lazennec JY, Catonné Y, PascalMoussellard H: Preoperative evaluation of the cervical spondylotic myelopathy with flexion-extension magnetic resonance imaging: about a prospective study of fifty patients. Spine (Phila Pa 1976) 36:E1134-E1139, 2011

38. Zoega B, Karrholm J, Lind B: Outcome scores in degenerative cervical disc surgery. Eur Spine J 9:137-143, 2000 